\title{
GEOSTATISTICAL METHODS EMPLOYED IN RESOURCE EVALUATION OF THE SNAP LAKE DIAMOND DEPOSIT, NWT, CANADA.
}

\author{
David Bush ${ }^{1}$, Fanie Nel ${ }^{1}$, Cliff Revering ${ }^{2}$ and Melissa Kirkley ${ }^{2}$ \\ ${ }^{1}$ De Beers Consolidated Mines, South Africa $\quad{ }^{2}$ De Beers Canada Mining Inc., Canada
}

\section{INTRODUCTION}

The Snap Lake deposit is a shallow dipping diamondiferous kimberlite dyke located approximately $220 \mathrm{~km}$ northeast of Yellowknife in the Northwest Territories of Canada.

To assess the potential of this deposit an estimate has to be made of its diamond content. The diamond potential is a function of the resource volume, the grade and dilution (avoidable and unavoidable.)

The aim of this paper is to demonstrate how various geostatistical techniques have been used to quantify some of the parameters required to define the mineral resource.

\section{GEOSTATISTICAL METHODS USED}

Geostatistics is a collection of statistical methodologies that incorporate the spatial nature of the variables under consideration.

Early applications of geostatistics were aimed at mapping the spatial distribution of a variable, for example the use of kriging to estimate the grade of a resource.

Recently, emphasis has fallen on using kriging to create models of uncertainty (Deutsch 1998). These methods, collectively known as simulation, allow the calculation of equally probable realizations of a spatial variable. The uncertainty associated with the estimate of the variable may then be gauged by the variation between each of the realizations.

Both of these methodologies were used to study the Snap Lake deposit. Conventional kriging techniques were used to estimate the proportion kimberlite within a mining unit (or block), while simulation was used to estimate the elevation of the dyke horizon and morphology of the deposit.

\section{Estimating tHe THICKNESS AND PROPORTION KIMBERLITE WITHIN EACH MINING BLOCK.}

Initial mine planning studies divided the deposit into 32 mining blocks. The kimberlite volume within each of these blocks had to be estimated.

\section{Data Preparation}

The deposit does not consist of a single sheet of kimberlite. Drill hole intersections and underground mapping have shown that, in part, the dyke splits into multiple seams.

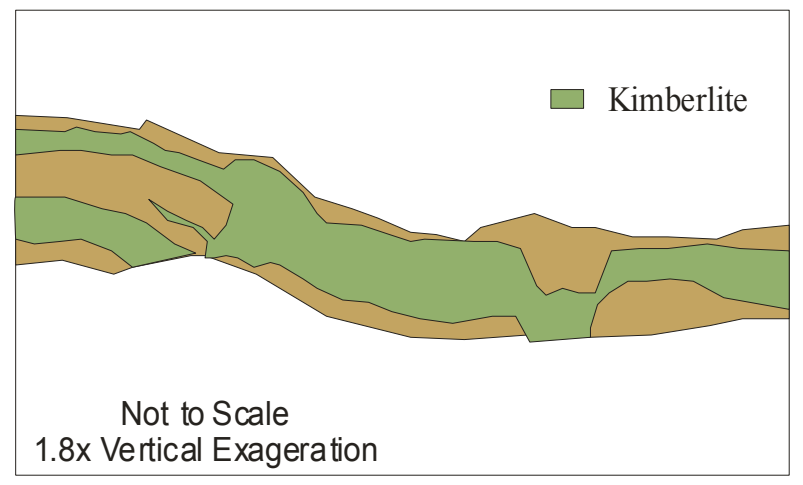

Figure 1 Section along the side wall of an ore drive.

Determining the volume of kimberlite in each mining block thus becomes more complex. The volume of kimberlite is a function of the width of a predetermined mining envelope and the proportion of kimberlite within that envelope.

The width of the resource envelope is based on economic considerations, and mining, legal and safety constraints.

Size limitations set by the mining methodology must also be taken into account. The planned mining methodology dictated that the envelope width should be at least $1.5 \mathrm{~m}$.

The mining envelope was defined by optimizing the proportion kimberlite in the mining width. Each of the drill hole intersections was examined and an envelope, 
thicker than $1.5 \mathrm{~m}$, was chosen so that it would contain the highest proportion kimberlite

The envelope thickness and proportion kimberlite were then regarded as regionalized variables and could be used like any other spatial variable in a geostatistical study.

\section{Estimation}

The thickness of the resource envelope was estimated using Ordinary kriging whilst Indicator kriging was used to estimate the proportion kimberlite.

Figures 2 and 3 show these results.

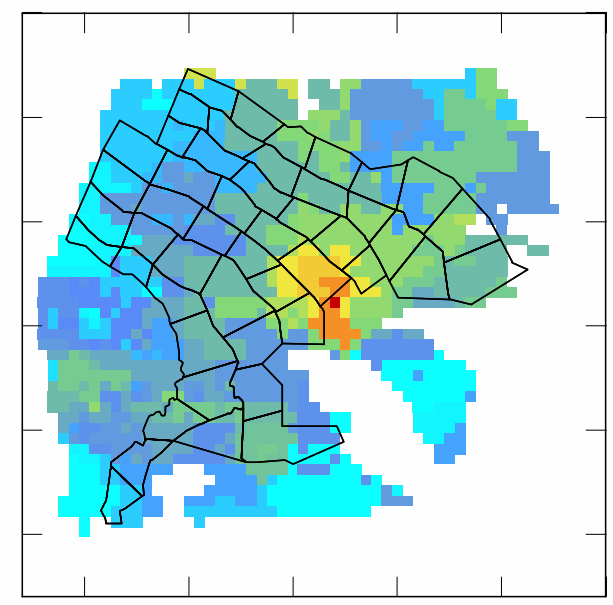

Figure 2. Estimated thickness of the resource envelope.

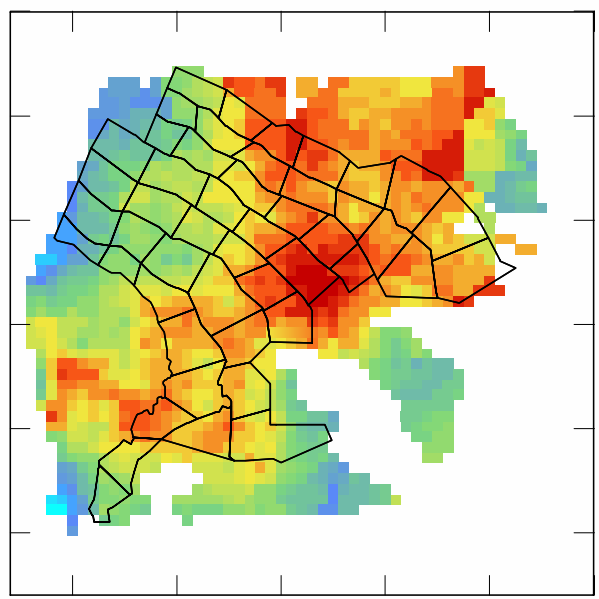

Figure 3. Estimated Proportion kimberlite within the mining envelope.

\section{SIMULATING THE DYKE ELEVATION.}

Conventional modeling techniques would interpolate the dyke intersections between drill holes as regular planar surfaces. These surfaces however show flat, angular facets, which do not adequately represent reality. Simulation of a surface reproduces the spatial properties of the dyke intersections, thus producing a more natural surface.

Simulation also allows for the calculation of confidence intervals around the most probable kimberlite surface. This could be useful during mine planning to ensure that footwall development does not intersect the mining envelope.

One hundred sequential gaussian simulations were calculated across the area. The average simulated values were used to show the most likely kimberlite surface.

The simulation process generates a surface that honors the statistical properties, both spatial and classical, of the actual dyke intersections. Any one of the simulation realizations could have given rise to the sampling data and is one possible outcome of the truth. Generating many outcomes of the possible real surface shows the most probable position of the surface as well as the range of possible outcomes. Areas of uncertainty can be quantified in this way.

Figure 4 shows the average surface created by the simulations. This is the most probable location of the dyke. The section presented in Figure 5 shows the average surface and the upper and lower 95\% confidence surfaces. As expected in 95 out of 100 simulations the dyke fell between these limits. Note that at the edges of the area, the confidence surfaces are wider. This is a direct function of the number of samples, ie drill hole intersections of the dyke. 


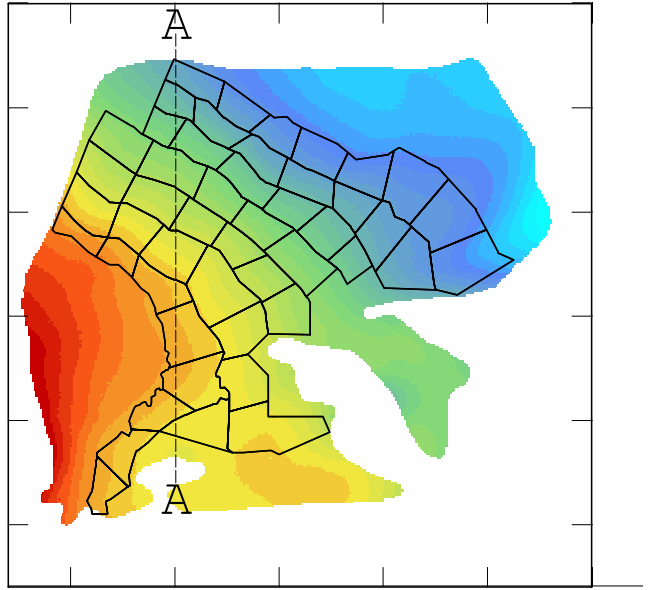

Figure 4. Elevation of the dyke intercept.

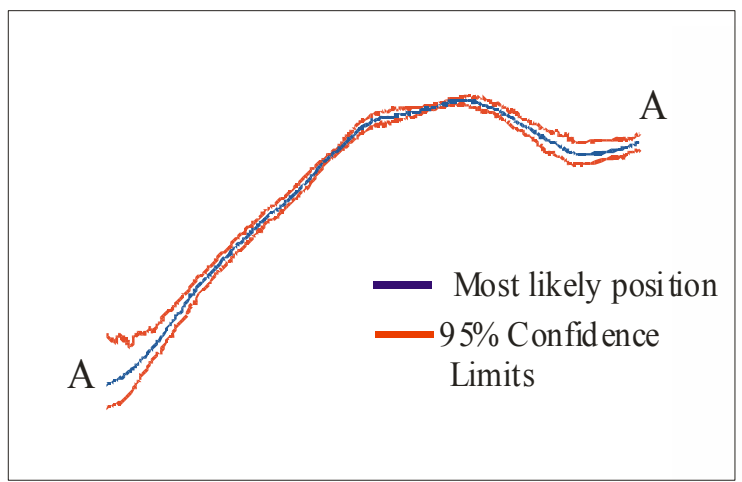

Figure 5. Section A-A. Dyke intersection and confidence intervals.

\section{SIMULATING THE DYKE MORPHOLOGY.}

The aim of this simulation was to produce a local 'image' of the dyke. A block model with a resolution of $1 \times 1 \mathrm{~m}$ area and $0.1 \mathrm{~m}$ thickness was simulated. This block model should reflect the sampled characteristics of the deposit. It should contain the correct amount of kimberlite, the spatial distribution of kimberlite should be consistent with reality, and actual samples should be honored. The simulation should look and 'feel' feasible.

Plans are in place to virtually mine these simulations to determine the best mining method. Different methods will be compared to evaluate costs, waste generation and even geotechnical constraints.

The spread of the kimberlite blocks within the ore envelope was characterized by:

- An Indicator variogram

- A Proportion curve

The simulations were done using the Truncated Gaussian Simulation implemented in the Isatis $\odot$ package. A decision to mark a block as kimberlite was based on the proportion curve and the variograms. The blockmodel was populated with waste and kimberlite blocks while honoring the sample data.

Figure 6 shows a typical section through the simulation.

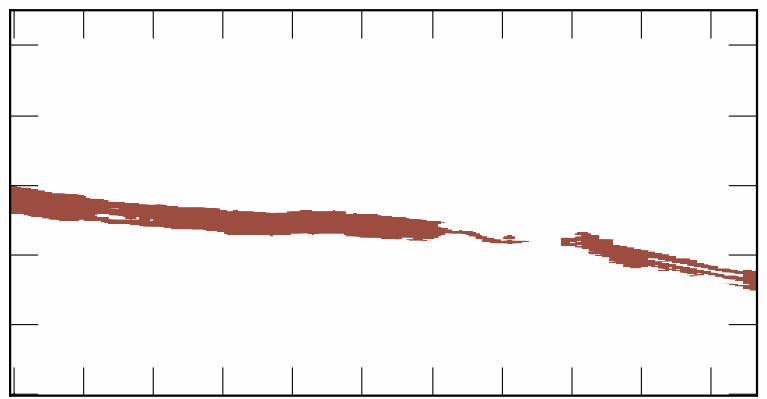

Figure 6. Section through the simulated dyke.

Figures 7 to 9 show how various properties mapped in the real dyke are reflected in that simulation.

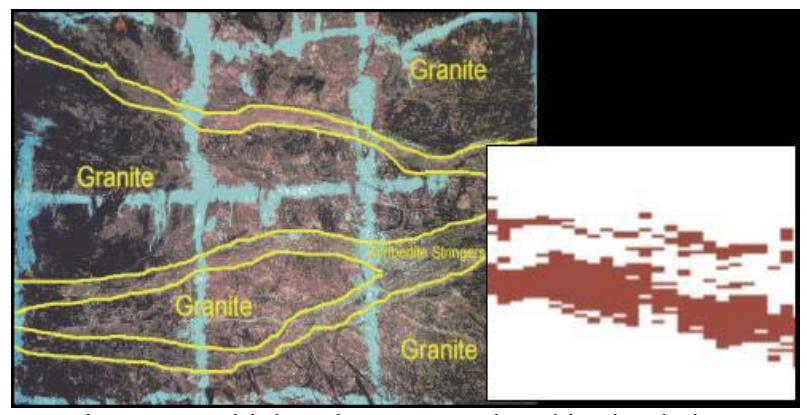

Figure 7. Multiple stringers reproduced in simulation. 


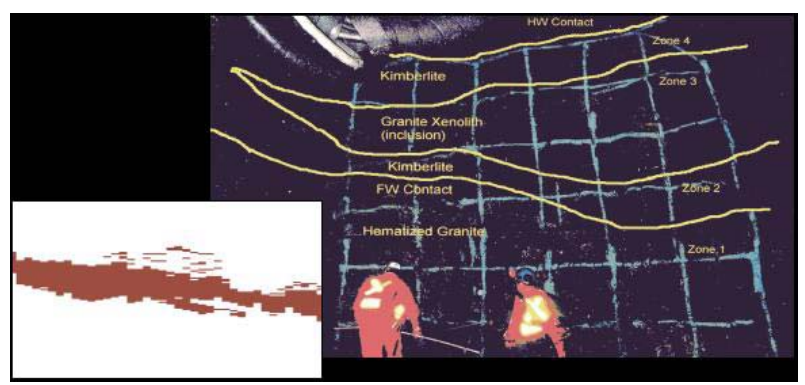

Figure8. Bifurcation reproduced.

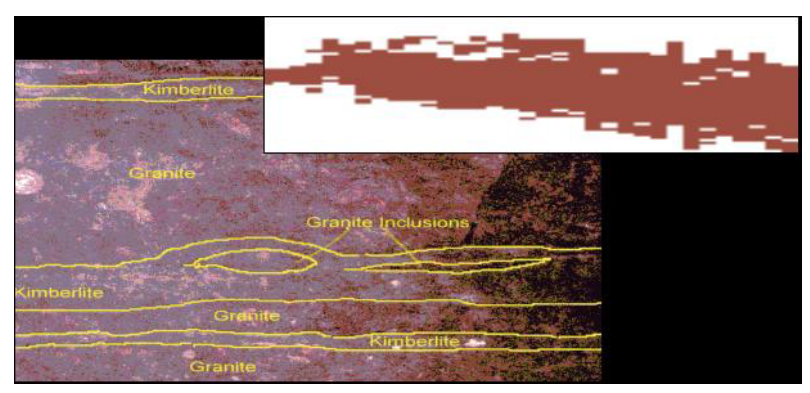

Figure 9. Internal waste reproduced.

Morphological simulations of the dyke are potentially very useful for this project. Conditional simulation of the resource will allow delineation of an optimal resource envelope ahead of the face. The simulation will show the most probable distribution of kimberlite ahead of mining and allow an optimum mining cut to be designed for a specific mining unit.

\section{CONCLUSIONS}

Geostatistical techniques are proving to be invaluable in exploring the morphology of the Snap Lake resource. A considerable advantage of these applications is that 'virtual' mine scenarios can be generated and optimized within mining, geotechnical, legal and safety constraints.

\section{REFERENCES}

Deutsch, C.V., Journel, A.G., 1998. GSLIB Geostatistical Software Library and User's Guide. Oxford University Press, Oxford.

Contact: F. Nel., De Beers, Private Bag 1,Southdale, 2135 , South Africa, E-mail: fanie.nel@debeersgroup.com. 